\title{
6.3. THE DETECTION OF CHANGES IN THE COORDINATES OF A PLACE ON THE EARTH
}

\author{
R.O. VICENTE \\ (Faculty of Sciences, Lisbon, Portugal)
}

\begin{abstract}
The accuracies involved in determining the motion of the pole and continental drift are discussed.

\section{RÉSUMÉ}

On discute les précisions requises pour déterminer le mouvement du pôle et la dérive des continents.
\end{abstract}

This paper computes the highest precision that can be attained by present-day methods for the observations of latitude, longitude and azimuth of a place. It is pointed out that there are only a restricted number of places on the Earth, at the present time, which can contribute to the detection of motions at the Earth's surface, and that most of these places are probably not situated in the regions of the Earth best suited for the researches concerned with motions in the upper layers of the Earth.

It is concluded that the highest precision, obtained by astronomical observations made during one night, of the coordinates of a point on the surface of the Earth gives a standard deviation of the order of $2.5 \mathrm{~m}$ in latitude and time determination. These values can be slightly improved by extending the period of observations. The precision obtained in observations of an astronomical azimuth is about 3 times lower. Attention is called to a certain number of systematic errors whose influence on the observations is not yet very well known.

It is stated that to observe motions of the ground of an order of magnitude of $0.25 \mathrm{~m}$ per year, and always in the same direction, we shall need at least 20 years and, even so, the standard deviation of the observations would be $50 \%$ of the displacement.

These values suggest that checking of possible motions of points on the surface of the Earth by astronomical observations is a very difficult task. 